\title{
Endoscopic Removal of Tangled Plastic Wires in the Stomach Using an Argon Plasma Coagulation and Endoscopic Scissors
}

\author{
Chang Kook Park, Ho Dong Kim, Ju Young Kim, Suk Je Jin, Byung Ki Kim, Yu Jeong Hwang, Do Hyun Kim \\ Department of Internal Medicine, Saint Carollo Hosipital, Suncheon, Korea
}

\begin{abstract}
Plastic wires are uncommonly swallowed and subsequently may be tangled in the stomach. Although endoscopy with accessories is effective for removal of most wires, sometimes it is hard to remove tangled plastic wires. Early diagnosis and immediate retrieval of ingested wires are important. Mentally impaired adults have a relatively high rate of surgical intervention and complications due to delayed diagnosis. A twenty-one year old woman visited our hospital with foreign bodies in the stomach. She was mentally retarded and had swallowed plastic wires frequently. Esophagogastro-duodenoscopy revealed tangled plastic wires. We cut three wires with argon plasma coagulation and endoscopic scissors to unwind the bundle of wires. We removed the remaining 17 wires one by one. The total length of the wires were $496 \mathrm{~cm}$. We report this unusual case of tangled plastic wires in the stomach removed endoscopically without surgical intervention. (Korean J Helicobacter Up Gastrointest Res 2015;15:124-126)
\end{abstract}

Key Words: Endoscopy; Foreign bodies; Argon plasma coagulation

\section{INTRODUCTION}

Although $80 \%$ to $90 \%$ of foreign bodies ingested have been reported to pass spontaneously through the gastrointestinal tract, ${ }^{1}$ approximately $10 \%$ to $20 \%$ require endoscopic intervention and approximately $1 \%$ may need surgical exploration and extraction. ${ }^{2-4}$

The majority of foreign body ingestions occur in the pediatric population, with a peak incidence between the ages of 6 months and 6 years. ${ }^{5}$ In adults, true foreign body ingestion occurs more commonly in those with psychiatric disorders, developmental delay, alcohol intoxication, and in incarcerated individuals seeking secondary gain via release to a medical facility. ${ }^{6,7}$ Ingestion of multiple foreign objects and repeated episodes of ingestion are common.

Young children, mentally impaired adults, and those with psychiatric illness may thus present with choking, refusal to eat, vomiting, drooling, wheezing, blood-stained saliva, or respiratory distress.

Here, we described a case of tangled plastic wires that

Received: October 31, 2014 Accepted: March 31, 2015

Corresponding author: Ho Dong Kim

Department of Internal Medicine, Saint Carollo Hospital, 221 Sungwang-ro, Suncheon 540-719, Korea

Tel: +82-61-720-2127, Fax: +82-61-720-6159, E-mail: raphael65@hanmail.net were removed with an argon plasma coagulation (APC) and endoscopic scissors in a mentally impaired adult.

\section{CASE REPORT}

A 21-year-old woman visited a local clinic due to refusal to eat food. She was mentally retarded and had swallowed plastic wires frequently. Esophagogastroduodenoscopy (EGD) was performed and showed foreign bodies in the stomach. She came from a local clinic for foreign

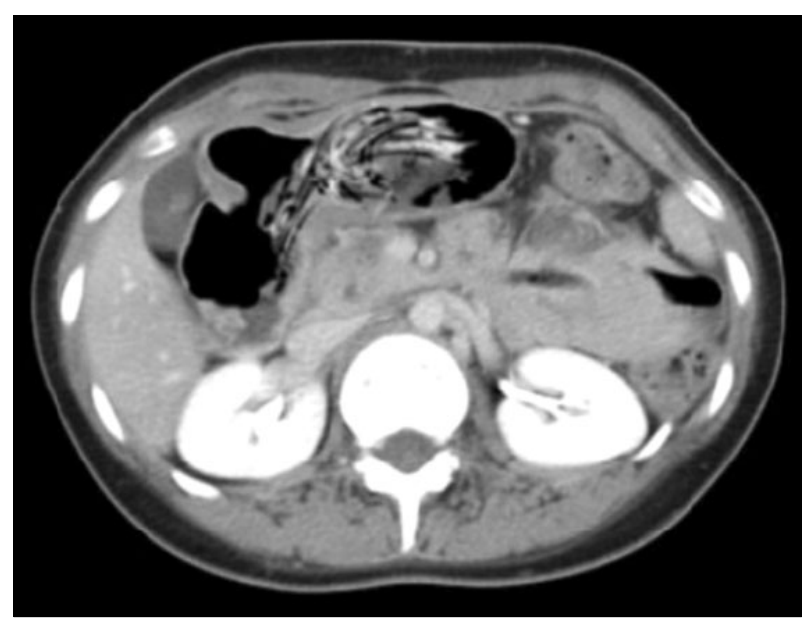

Fig. 1. Abdominal computed tomography showed about $7 \mathrm{~cm}$ mixed attenuated lesion in the gastric antrum.

Copyright $\odot 2015$ Korean College of Helicobacter and Upper Gastrointestinal Research

↔ The Korean Journal of Helicobacter and Upper Gastrointestinal Research is an Open-Access Journal. All articles are distributed under the terms of the Creative Commons Attribution Non-Commercial License (http://creativecommons.org/licenses/by-nc/4.0) which permits unrestricted non-commercial use, distribution, and reproduction in any medium, provided the original work is properly cited. 
body removal. She complained of epigastric discomfort. Laboratory tests were within normal limits, and chest radiograph was normal. Abdominal computed tomography showed about $7 \mathrm{~cm}$ mixed attenuated lesion in gastric antrum and several small bowel intussusceptions in left abdomen and pelvis (Fig. 1). EGD revealed many multi-colored plastic wires with strings and food in the stomach (Fig. 2A). We cut multiple strings with an endoscopic scissors and removed ahead. We grasped a wire and pulled out it to remove one by one. However, all wires were moved together because the wires were all tangled up. It was too big to pass through the lower esophageal sphincter (Fig. 2B). Furthermore, it was impossible to unbind them. We attempted to cut the wire with an endoscopic scissors. It was unsuccessful to cut with an endoscopic scissors because those were too stiff and slippery
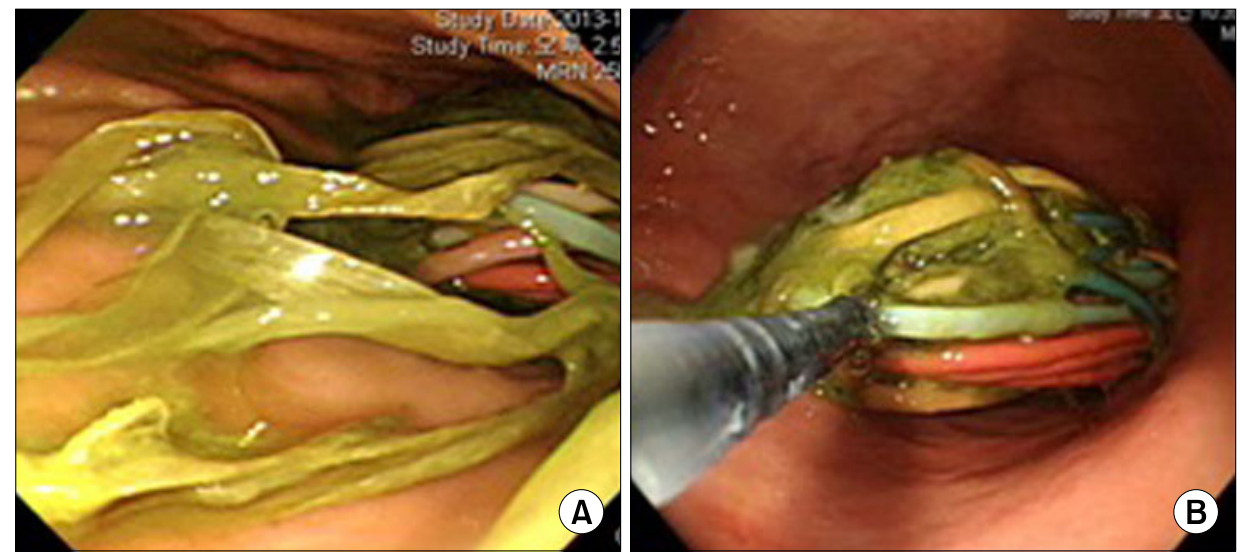

Fig. 2. (A) The endoscope revealed that the wires were all tangled up together with strings. (B) It was impossible to remove them en bloc.
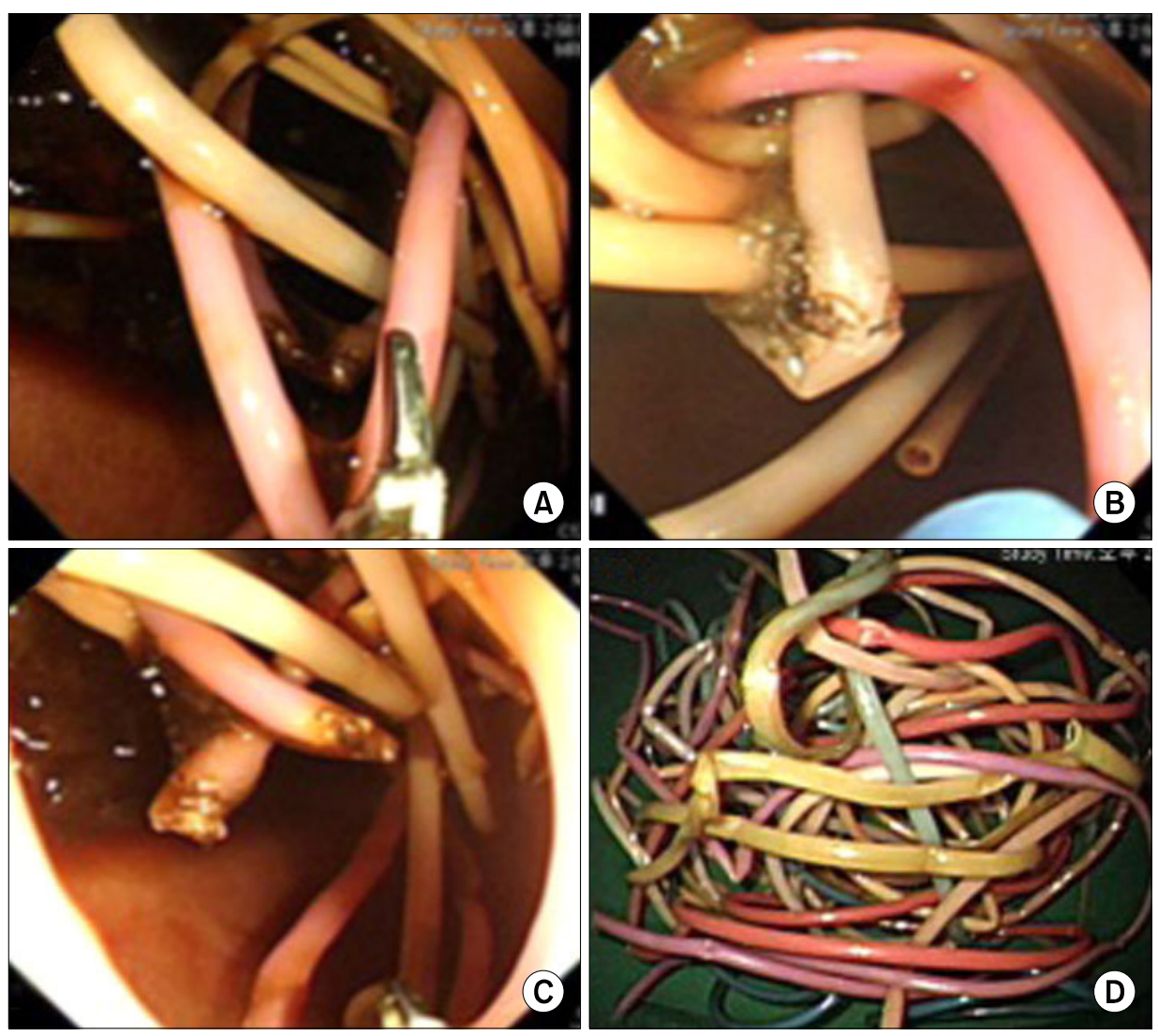

Fig. 3. (A) Plastic wires were too stiff and slippery to cut with an endoscopic scissors. (B) argon plasma coagulation (APC) for burning food of plastic wires to make small damage. (C) Plastic wire was cut with an endoscopic scissors after APC. (D) The wires were untangled and pulled out each. 
(Fig. 3A). We took APC to try to damage the wire. As we all know, damages did not occur at plastic wire. However, when APC was used on food of plastic wire, the tissue effect of APC was created on food. The damage at the wire under food was made by APC (Fig. 3B). The wire had a small indentation. However, even though APC was used continuously, additional damages did not appear after the burnt out of food. We used an endoscopic scissors to cut the wire. The wire was cut after all (Fig. 3C). We cut three wires to unwind a bundle of wires in the same way. The wires were untangled and we pulled out all wires one by one (Fig. 3D). The number of wires was 17. The total length of wires was $496 \mathrm{~cm}$. She ate well after removal of wires. There were no intussusceptions on follow-up CT.

\section{DISCUSSION}

The majority of ingested foreign bodies will pass spontaneously without complications. However, 2 recent studies have shown that in the setting of intentional ingestion, the rate of endoscopic intervention may be much higher $(63 \sim 76 \%)$ and the need for surgical intervention ranges from $12 \%$ to $16 \%{ }^{6,8}$

Most of the incidents were intentional ingestions of common household items, such as toothbrushes, pens, and plastic spoons, rather than the accidental food and bone impactions commonly described in previous reports in patients with underlying psychiatric problems. ${ }^{6}$

Several key factors influence the management of foreign body ingestion: physical characteristics of the foreign body, time elapsed since ingestion, location of the foreign body, and evidence of associated complications.

A wire in the stomach is removed easily with an endoscope. On the other hand, it is hard to remove multiple wires in the stomach. As time goes by, multiple wires get entangled and make a bundle. It is impossible to remove the bundle en bloc. Sometimes an endoscopic scissors is useful to cut a string such as a detachable snare. However, plastic wires are too stiff to cut with an endoscopic scissors.

APC has been used to provide tissue coagulation and haemostasis. ${ }^{9}$ The tip of the catheter is held close to the tissue to be treated, and the current arcs across to the tissue causing a superficial $(2 \sim 3 \mathrm{~mm})$ burn. As might be expected, APC did not make any damage on a plastic wire itself. However, APC caused burns on food of the wires and made small indentations on plastic wires interestingly. Finally, the wires were friable. We cut three wires to unwind the bundle with an endoscopic scissors. We safely removed the bundle of plastic wires.

We used two different devices to cut plastic wires and remove the bundle of plastic wires successfully.

\section{REFERENCES}

1. Smith MT, Wong RK. Esophageal foreign bodies: types and techniques for removal. Curr Treat Options Gastroenterol 2006;9:75-84.

2. Webb WA. Management of foreign bodies of the upper gastrointestinal tract: update. Gastrointest Endosc 1995;41:39-51.

3. Webb WA. Management of foreign bodies of the upper gastrointestinal tract. Gastroenterology 1988;94:204-216.

4. Chaves DM, Ishioka S, Félix VN, Sakai P, Gama-Rodrigues JJ. Removal of a foreign body from the upper gastrointestinal tract with a flexible endoscope: a prospective study. Endoscopy 2004; 36:887-892.

5. Hachimi-Idrissi S, Corne L, Vandenplas Y. Management of ingested foreign bodies in childhood: our experience and review of the literature. Eur J Emerg Med 1998;5:319-323.

6. Palta R, Sahota A, Bemarki A, Salama P, Simpson N, Laine L. Foreign-body ingestion: characteristics and outcomes in a lower socioeconomic population with predominantly intentional ingestion. Gastrointest Endosc 2009;69:426-433.

7. Blaho KE, Merigian KS, Winbery SL, Park LJ, Cockrell M. Foreign body ingestions in the emergency department: case reports and review of treatment. J Emerg Med 1998;16:21-26.

8. Weiland ST, Schurr MJ. Conservative management of ingested foreign bodies. J Gastrointest Surg 2002;6:496-500.

9. Grund KE, Storek D, Farin G. Endoscopic argon plasma coagulation (APC) first clinical experiences in flexible endoscopy. Endosc Surg Allied Technol 1994;2:42-46. 